\title{
Hydraulics of bendway weirs
}

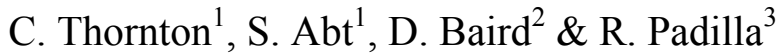 \\ ${ }^{1}$ Colorado State University, Fort Collins, CO, USA \\ ${ }^{2}$ U.S. Bureau of Reclamation, Denver, CO, USA \\ ${ }^{3}$ U.S. Bureau of Reclamation, Albuquerque, NM, USA
}

\begin{abstract}
Natural processes associated with meandering river systems have been shown to lead to degradation of channel beds, erosion on channel banks, and bend migration. Attempts at mitigating the local instability associated with meandering systems, such as transverse and longitudinal structures, armor protection, and bio-engineering techniques have been utilized worldwide. One type of structure, bendway weirs, are rock structures placed in series along the outer bank of a bend in an effort to alleviate stresses, as well as create habitat. Many aspects associated with the bendway weir indicate the structure to be a viable alternative to longitudinal stone toe for controlling migration and bank erosion. While bendway weirs have been successfully used in many applications, quantifiable design guidance has not been available. Past projects utilizing bendway weirs have relied heavily on field experiences, site-specific flume studies, and engineering judgment, but have lacked general design guidelines. To accurately model flow conditions resulting from the placement of bendway weirs, an undistorted 1:12 Froude scale, hard boundary model was constructed at the Hydraulics Laboratory of the Engineering Research Center at Colorado State University. The model contained two bends, which exhibited unique geometric characteristics representative of those found in the Middle Rio Grande reach. Three-dimensional velocities and water surface profiles were recorded for a series of tests including variations of weir length, spacing, and angle. Using the data obtained from the test series, a relationship of the reduction of velocities relative to pre-weir conditions, due to the variation of bendway weir characteristics, was developed. The location of the strongest eddies found in a bend as a function of weir length was also examined. Bendway-weir testing resulted in the creation of design criteria. Utilization of a known set of base-line conditions for a given bend and design parameters for bendway weirs, a designer is enabled to predict maximum velocities found in the bend after the installation of bendway weirs.
\end{abstract}

Keywords: bendway weirs, river restoration, bank erosion, in-stream structures. 


\section{Introduction}

Bank erosion and channel migration are natural responses to a shift in the equilibrium of a river system. Natural changes in river systems have impacted navigation and the use of adjacent land for hundreds of years. There have been several methods developed for alleviating bank instability and managing channel migration. The use of rock, riprap, and concrete structure techniques have been popular methods implemented in bank stabilization. More specifically, the use of a riprap blanket placed over an eroding bank, although extremely effective in preventing bank erosion, is not conducive to the enhancement of habitat. Blanketing a portion of a stream bank with riprap hinders the growth of riparian vegetation and favorable aquatic habitat features.

Historically bendway weirs, also known as spur dikes, groins, or jetties, have been used extensively in the deepening of navigational channels. It has been documented that in their application to navigation channels, the rock weir structures were also an effective method of bank stabilization. The use of bendway weirs was then extended to river restoration and rehabilitation projects. They have been a useful tool in stabilizing bend migration and outer bank erosion, as well as promoting aquatic habitat and riparian vegetation (Shields et al. [1]). Figure 1 presents a photograph of a series of bendway weirs placed on a river bend.

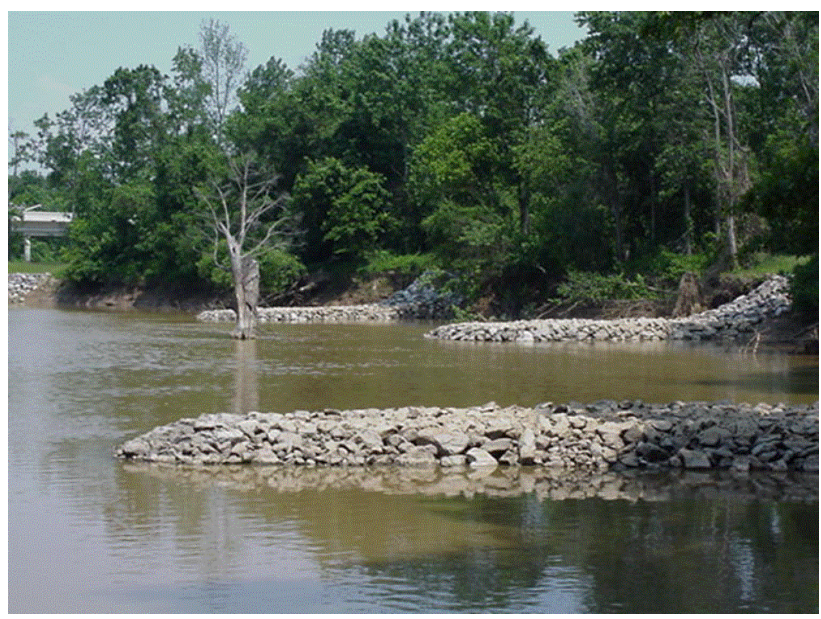

Figure 1: $\quad$ Example of bendway weirs in the field.

While the bendway weir has been used and studied for several decades, design guidelines for the use of bendway weirs have, to date, not been successfully developed. Major design parameters of the bendway weir include height, length, orientation angle, and spacing. Current guidance on the design of these rock structures is based on field experience and rule-of-thumb. To date, the behavior of flow conditions following the installation of bendway weirs has 
not been empirically defined. As an initial step in quantifying the flow conditions resulting from bendway weir placement, a physical hydraulic model was constructed and tested to determine the effects of weir spacing on the resulting flow conditions.

\section{Physical model}

A 29-mile stretch of the Rio Grande, located in central New Mexico extending from Cochiti Dam to the town of Bernalillo, has been the focus of a channel maintenance project conducted by the U.S. Bureau of Reclamation. As part of that maintenance project, the Bureau desired to employ native material and rock weir structures in an effort to mitigate bank erosion, channel migration, and habitat degradation. Upon realizing that design criteria for native material and rock weir structures was scarce and limited, a physical hydraulic model study was contracted for and conducted at Colorado State University. The model was intended to determine the most effective design of bank-stabilization structures, i.e., bendway weirs, vortex weirs, veins, and turning rocks for use on the Middle Rio Grande.

An undistorted 1:12 Froude scale, hard boundary physical hydraulic model exhibiting characteristics represented in a 29-mile study reach of the Middle Rio Grande, extending from Cochiti Dam to the town of Bernalillo, was constructed for the testing of bendway weirs. The model consisted of two geometrically unique bends placed in an S-shaped configuration and separated by a straight transition section. Bendway weirs were then constructed from riprap and placed throughout each bend for testing. The model was equipped with an instrumentation and data-collection cart permitting measurements of flow depth, three-dimensional velocity, and boundary shear stress at any location within the model.

Cross-sectional geometry in both bends was chosen to be trapezoidal with a 1:3 side slope, which corresponds to conditions found within the study reach. To accommodate the required flow rates needed for testing, a total channel depth of $1.5 \mathrm{ft}(0.46 \mathrm{~m})$ and bed slope of 0.000863 were incorporated into the model. To achieve the goals of the study, a fixed bed was incorporated into the model. Throughout the prototype study reach, Manning's $n$ values ranged from 0.026 to 0.035 for the channel bed and banks. The model was, therefore, constructed with a roughened concrete surface that was determined to have a Manning's value of 0.018 , which related to prototype roughness of approximately 0.027 .

Flow depth and water surface elevation measurements were obtained using two methods. A standard point gage, capable of measuring $60.001 \mathrm{ft}(60.03 \mathrm{~cm})$, was mounted to the instrumentation cart allowing for bed and water surface measurements to be collected anywhere in the channel. In addition to the point gage, 122 piezometer taps were placed throughout the model. At each cross section, three taps were placed on the side slopes at varying elevations and one tap located in the center of the channel. A SonTek ${ }^{\circledR}$ Acoustic Doppler Velocity (ADV) meter was used to collect and record three-dimensional velocity profiles. The velocity measurement system included a data-acquisition card and software 
used on a personal computer to record velocity measurements at a selected sampling rate of $10 \mathrm{~Hz}$. A full description of data-collection techniques and locations can be found in Heintz [2].

Based on the literature review, an initial bendway weir design was determined. The influence of spacing on the flow characteristics and performance of bendway weirs was investigated by maintaining the height, length, width, and shape of the weirs while altering the weir spacing. The crest profile of the weir was chosen to be flat. Weir length was determined to be $28 \%$ of the channel top width at $12 \mathrm{cfs}(0.34 \mathrm{cms})$, also blocking $26.7 \%$ of the flow area in both bends. The weirs were installed perpendicular to the bank at an orientation angle of 90 degrees relative to the flow direction. Figure 2 illustrates the weir geometry in plan view and cross-sectional views. Table 1 presents the weir dimensions tested. The values in Table 1 remained constant for the testing sequences.

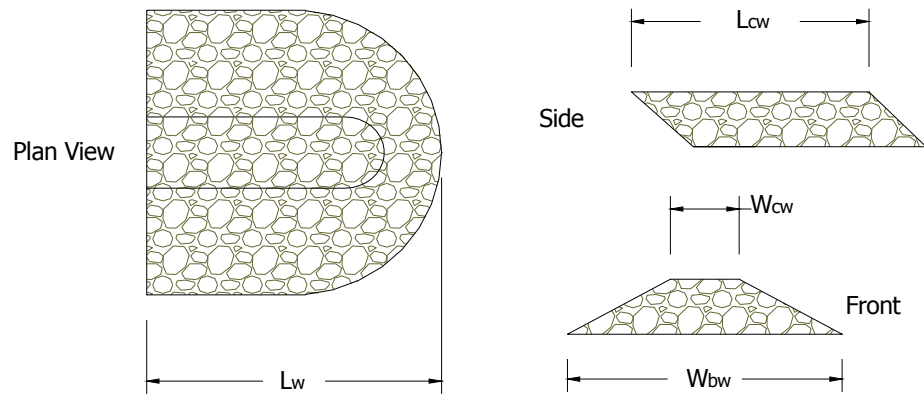

Figure 2: Bendway weir schematic.

Table 1: Weir dimensions.

\begin{tabular}{|l|c|c|}
\hline & Upstream Bend & Downstream Bend \\
\hline$L_{c w}$ & $4.07 \mathrm{ft}(1.24 \mathrm{~m})$ & $2.98 \mathrm{ft}(0.91 \mathrm{~m})$ \\
\hline$L_{w}$ & $4.90 \mathrm{ft}(1.49 \mathrm{~m})$ & $3.82 \mathrm{ft}(1.16 \mathrm{~m})$ \\
\hline$W_{c w}$ & $1 \mathrm{ft}(0.30 \mathrm{~m})$ & $1 \mathrm{ft}(0.30 \mathrm{~m})$ \\
\hline$W_{b w}$ & $4 \mathrm{ft}(1.22 \mathrm{~m})$ & $4 \mathrm{ft}(1.22 \mathrm{~m})$ \\
\hline$L_{r}=L_{w} / T W$ & 0.267 & 0.267 \\
\hline
\end{tabular}

Spacing ratio between weirs was defined in the literature review as the ratio between the distance separating the weirs and their length. Therefore, the spacing ratio, $S$, was defined by measuring the arc length between the weirs at the design water line along the bank, $L_{a r c}$, and dividing it by the total length of the weir, $L_{w}$, as defined in Figure 3 and eqn (1):

$$
S=\frac{L_{\text {arc }}}{L_{w}}
$$




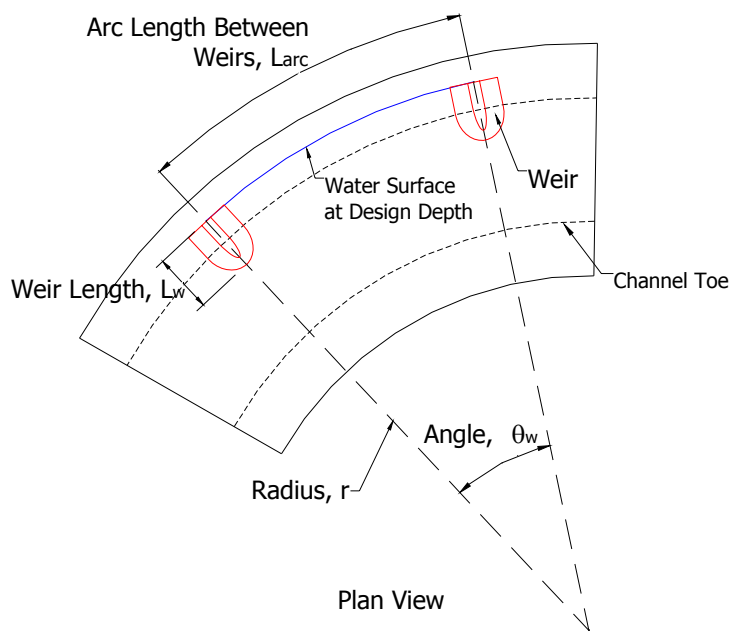

Figure 3: Definitions used in spacing ratio measurement.

Table 2: $\quad$ Tested spacing ratios.

\begin{tabular}{|l|c|c|}
\hline & Upstream Bend & Downstream Bend \\
\hline$S / \#$ of Weirs & $3.4 / 6$ & $4.7 / 5$ \\
\hline$S$ / \# of Weirs & $4.1 / 5$ & $5.9 / 4$ \\
\hline$S$ / \# of Weirs & $5.1 / 4$ & $8.4 / 3$ \\
\hline
\end{tabular}

Six different spacing ratios, three in each bend, were tested during the program. Table 2 presents the spacing ratios tested, as well as the corresponding number of weirs per bend.

\section{Test matrix}

A test matrix consisting of sixteen individual flume runs was developed to quantify the effect of spacing on the flow patterns and document performance of bendway weirs installed within a channel. A total of four tests were conducted without bendway weirs installed, and termed base-line tests, leaving twelve tests for examining the effect of bendway weirs on resulting flow conditions by varying the parameters described above.

An examination of data collected throughout each bend during each test was conducted to determine the influence of weir spacing on flow conditions. The maximum velocity measured on the outer bank of each bend during testing was examined in detail and a thorough description of that analysis is presented by Heintz [2].

Tests were conducted at four different discharges to simulate flow conditions present in the Middle Rio Grande study reach. Prototype flows simulated in the 
physical model include 4,000,6,000, 8,000, and 10,000 cfs $(113,170,227$, and $283 \mathrm{cms}$, respectively) corresponding to model flow rates of $8,12,16$, and $20 \mathrm{cfs}$ (0.23, 0.34, 0.45, and $0.57 \mathrm{cms}$, respectively).

\section{Dimensional analysis}

Several dimensionless terms were formulated for the analysis of bendway weir data. Dimensionless parameters that would describe the effects of weir spacing on performance were determined by considering the numerous variables describing the physically modeled system and are presented in detail by Heintz [2]. Data analysis was then carried out using a worst-case condition approach to developing design criteria by selecting maximum measured velocities. The initial conditions measured in the base-line tests were incorporated into the dimensional analysis to indicate changes in the flow created by weirs with varying spacing ratios.

Identification of the maximum velocity, $\operatorname{Max} V$, at a specific location in a bend (i.e., center, outer or inner bank) accounts for the most extreme velocity condition occurring during weir testing. The maximum velocity ratio, $M V R$, presented in eqns (2) through (4), at a specified location incorporates maximum velocity conditions with weirs relative to maximum centerline velocity measured during the base-line testing. Centerline velocity measured at $60 \%$ of the depth is representative of the cross-section average velocity, which would also be attainable from a field site visit or predictive computer model. The maximum base-line center velocity, $M a x V_{\text {CenterBase }}$, was incorporated into the MVR to develop a velocity-based design parameter conveniently adapted to field situations:

$$
\begin{aligned}
& M V R_{\text {Out }}=\frac{\text { MaxV }_{\text {Out }}}{\text { Max } V_{\text {CenterBase }}}, \\
& M V R_{\text {Center }}=\frac{M a x V_{\text {Center }}}{M a x V_{\text {CenterBase }}} \text {, and } \\
& M V R_{\text {In }}=\frac{M a x V_{\text {In }}}{\text { MaxV }_{\text {CenterBase }}},
\end{aligned}
$$

where, $M a x V_{\text {Out }}=$ maximum velocity measured between weirs on the outer bank $(\mathrm{L} / \mathrm{T}) ; M a x V_{\text {Center }}=$ maximum centerline velocity measured during weir testing $(\mathrm{L} / \mathrm{T}) ; \operatorname{Max}_{I n}=$ maximum inner bank velocity measured during weir testing $(\mathrm{L} / \mathrm{T}) ; \operatorname{Max}_{\text {CenterBase }}=$ maximum base-line center velocity at $60 \%$ depth $(\mathrm{L} / \mathrm{T})$; $M V R_{\text {Out }}=$ outer bank maximum velocity ratio (dimensionless); $M V R_{\text {Center }}=$ 
centerline maximum velocity ratio (dimensionless); and $M V R_{I n}=$ inner bank maximum velocity ratio (dimensionless).

\section{Analysis}

The concept of a velocity ratio, $M V R$, presented in eqns (2) through (4), was used to develop relationships between maximum measured centerline velocity values during the base-line runs with the maximum recorded velocity at three lateral cross-section locations when bendway weirs were installed in the model. Maximum measured velocity values along the outer bend, inner bend, and thalweg during tests 5 through 16 were determined and utilized in the analysis. A detailed description of the location of each velocity value incorporated into the analysis has been reported by Heintz [2].

The outer bank maximum velocity ratio, $M V R_{\text {Out }}$, was calculated using the MaxV $V_{\text {Out }}$ and MaxV $_{\text {CenterBase }}$ values recorded during each test. A plot of determined $M V R_{O u t}$ values versus spacing ratio is presented in Figure 4.

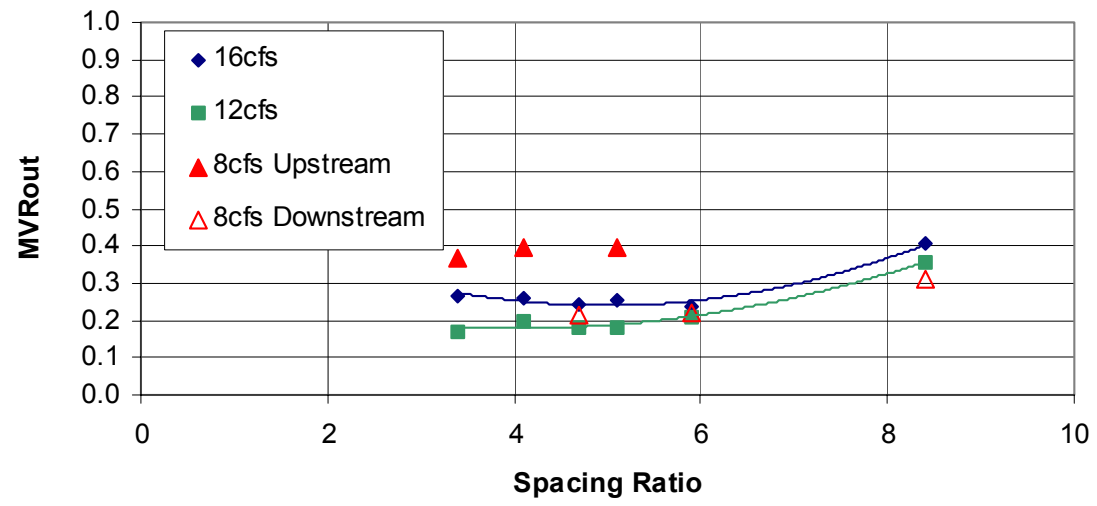

Figure 4: $\quad M V R_{\text {Out }}$ plotted versus spacing ratio.

Figure 4 shows that weirs at varying spacing ratios effectively reduce the outer bank velocity to at least $40 \%$ of the maximum centerline velocity. Therefore, any bend with a bendway weir field designed with the same length ratio, orientation angle, and having a spacing ratio of 8.4 or less will have its outer bank velocity reduced to at least $40 \%$ of the maximum centerline velocity. Using velocity output from a predictive HEC-RAS model, or center channel velocity measured in the field, it is possible for a designer to determine the maximum expected velocity for the outer bank of a bend with a specific geometry.

Differences between the overtopping and non-overtopping flows remain apparent in Figure 4. The overtopping flow data plotted in Figure 4 indicate that there is no dependence on spacing ratio up to a value of $S=6$. In both bends, the $M V R_{\text {Out }}$ values during overtopping tests were 0.25 for the $16 \mathrm{cfs}(0.45 \mathrm{cms})$ test and 0.19 for the $12 \mathrm{cfs}(0.36 \mathrm{cms})$ test. These values are even less than the 
overall value of $40 \%$. However, the $M V R_{\text {Out }}$ data for overtopping flow conditions present two separate relationships corresponding to the 12 and $16 \mathrm{cfs}$ ( 0.36 and $0.45 \mathrm{cms}$, respectively) flow rates. The non-overtopping flow exhibits a much different condition between the upstream and downstream bends, which is attributed to unusually high maximum velocities measured on the outer bank in the upstream bend as previously discussed.

An examination of the center and inner bank flow characteristics was conducted to determine the changes induced by weirs with varying spacing ratios. The same analysis as conducted on the outer bank was performed for the centerline and inner bank locations. A direct comparison between base-line and weir data collected at the center and inner bank of the channel was also investigated.

Figure 5 presents the $M V R_{\text {Center }}$ plotted versus spacing ratio, $\mathrm{S}$, and indicates that the $M V R_{\text {Center }}$ has no dependence on the spacing ratio. The plot indicates that the centerline velocity with the placement of weirs is on average 1.422 times greater than the initial maximum centerline velocity, with a standard deviation of 0.139. Therefore, a designer may expect the centerline velocity to increase to a maximum of 1.69 times greater than the maximum centerline velocity without weirs, determined by a predictive computer model or field measurements, with $95 \%$ confidence.

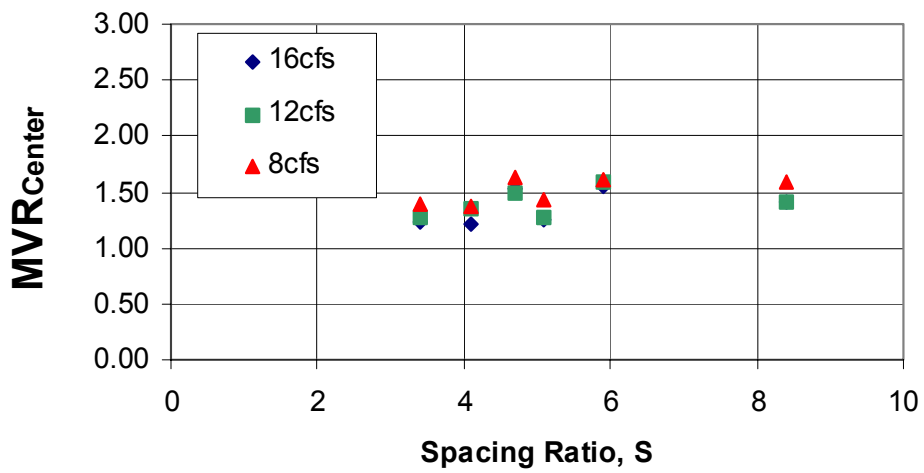

Figure 5: $\quad M V R_{\text {Center }}$ plotted versus spacing ratio.

Effects of weir spacing on the inner bank velocities was also investigated. Techniques applied during the outer bank analysis employed on the data collected along the inner bank of each bend. A direct comparison between weir and base-line data on the inner bank was conducted similar to the centerline comparison analysis.

Results of the $M V R_{I n}$ analysis are presented in Figure 6. As indicated on the plot, there is an increase in inner bank velocity with respect to the center velocity, which is fully independent of weir spacing and bend. The inner bank velocity for all tests was determined to be an average of 1.478 times greater than the base-line center velocity, with a standard deviation of 0.044 . The resulting $M V R_{I n}$ value is 1.56 , indicating that with $95 \%$ confidence that the inner bank 
velocity will increase to a maximum of 1.56 times the maximum centerline velocity without weirs. The $M V R$ value enables a designer to determine the maximum inner bank velocity expected after weir construction by providing a maximum center velocity in the channel prior to weir placement.

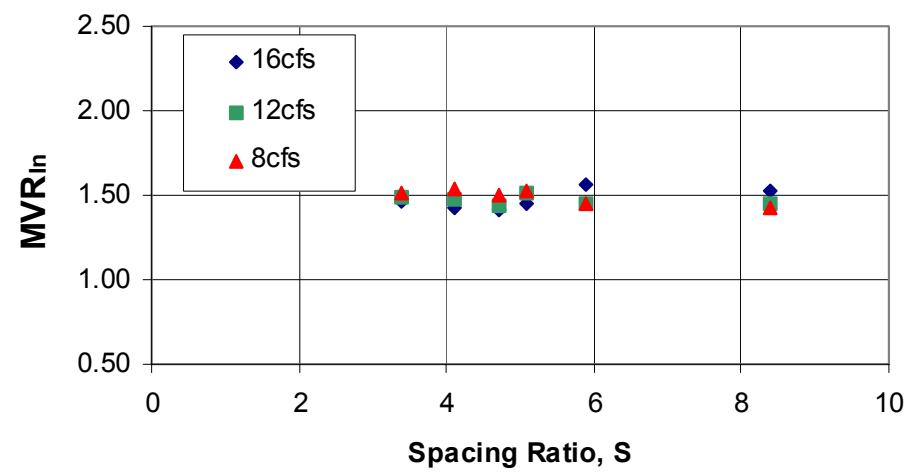

Figure 6: $\quad M V R_{I n}$ plotted versus spacing ratio.

\section{Conclusions}

The bendway weir has been used for several decades as an effective method for mitigating bank and bend stabilization problems. Design of the bendway weir in the field has been primarily based on field experience and engineering judgment, not hard design criteria. Weir features that are of interest in the design process include weir height, length, orientation angle, and spacing. The study presented has examined two separate bends with varying geometries to determine their flow characteristics and the changes to those characteristics as a result of bendway weir placement. Furthermore, this study has investigated the role of weir spacing on flow conditions while holding weir geometry constant.

An analysis of bendway weir spacing tests revealed that the spacing ratio of $\mathrm{S}$ less than 6 has little influence on maximum flow conditions in the two bends as a result of bendway weir placement. The maximum velocity measured on the outer bank between weirs for all tests was approximately $40 \%$ or less of the maximum centerline velocity measured without weir placement. Placement of the bendway weir fields did significantly reduce the outer bank velocity. Outer bank maximum velocity conditions for non-overtopping flow conditions were a result of eddy formation between weirs. Maximum velocities between weirs for non-overtopping flow conditions were as high or higher than maximum velocities measured during overtopping conditions. The maximum centerline velocity was increased by a factor of 1.69 with the placement of weirs. Maximum inner bank velocity measured during all weir tests was determined to be 1.56 times greater than the maximum center velocity measured during baseline testing. Trends in the inner bank velocity ratio relationship in both bends were maintained for all weir testing, even though center and inner bank 
velocities increased with weir placement. Based on the results presented by Heintz [2], weir length and not weir spacing was found to be the dominant factor in the resulting hydraulic conditions within the bendway weir field.

\section{References}

[1] Shields Jr., F.D., Knight, S.S. \& Cooper, C.M., Addition of spurs to stone toe protection for warmwater fish habitat rehabilitation. Journal of the American Water Resources Association, 34(6), pp. 1427-1436, 1998.

[2] Heintz, M.L., Investigation of Bendway Weir Spacing. MS Thesis, Department of Civil Engineering, Colorado State University, Fort Collins, CO, 2002. 